\title{
ASUHAN KEBIDANAN KOMPREHENSIF PADA NY “C” P2002 DENGAN POST HPP KARENA RETENSIO PLASENTA DI RSUD dr.SOEGIRI LAMONGAN TAHUN 2015
}

\author{
Siti Aisyah* \\ Apriska WulanSari** \\ *Dosen Program Studi Diploma III Kebidanan Universitas Islam Lamongan \\ **Mahasiswa Program Studi Diploma III Kebidanan Universitas Islam Lamongan
}

\begin{abstract}
ABSTRAK
Penelitian ini untuk mengembangkan pola pikir dalam melaksanakan asuhan kebidanan dengan menggunakan manajemen kebidanan (SOAP) pada Ny "C" P2002 dengan HPP karena retensio plasenta Di RSUD dr. Soegiri Lamongan Tahun 2015. Metode yang dipakai dalam penyusunan penelitian ini deskriptif observasi yang di laksanakan dengan pendekatan kohort mulai dari kehamilan sampai kontrasepsi yang diperoleh melalui wawancara, pengkajian data primer, sekunder, pemeriksaan fisik, penunjang dan dilakukan pendokumentasian standar asuhan kebidanan dengan menggunakan SOAP. Berdasarkan hasil studi kasus diperoleh data subyektif terdapat kesenjangan antara tinjauan pustaka dan tinjauan kasus pada keluhan utama. Pada data obyektif tidak terdapat kesenjangan antara tinjauan teori dengan tinjauan pustaka yaitu pada pemeriksaaan fisik. Pada analisa terdapat kesenjangan antara tinjauan kasus dengan tinjauan pustaka yaitu pada masalah potensial. Pada penatalaksanaan tidak terdapat kesenjangan antara tinjauan pustaka dan tinjauan kasus.
\end{abstract}

\section{Kata Kunci : Retensio Plasenta, HPP, Hari ke1}

\section{PENDAHULUAN}

Masa nifas (puerperium) dimulai setelah kelahiran plasenta dan berahir ketika alat-alat kandungan kembali seperti keadaan sebelum hamil.Masa nifas berlangsung kira-kira 6 minggu.

Perdarahan postpartum merupakan salah satu faktor terjadinya komplikasi dalam masa nifas yang mengakibatkan tingginya angka kematian ibu, maka fokus utama asuhan persalinan normal adalah mencegah terjadinya perdarahan. Pencegahan perdarahan pada saat persalinan akan mengurangi terjadinya komplikasi selama masa nifas dan akan mengurangi kematian ibu.

Faktor-faktor yang menyebabkan perdarahan post partum adalah grande multipara, jarak persalinan yang pendek kurang dari 2 tahun, persalinan yang dilakukan dengan tindakan: pertolongan kala III uri sebelum waktunya, pertolongan persalinan oleh dukun, persalinan dengan tindakan paksa.

Perdarahan post partum merupakan salah satu faktor terjadinya komplikasi dalam masa nifas yang mengakibatkan tingginya angka kematian ibu, maka fokus utama asuhan persalinan normal adalah mencegah terjadinya perdarahan. Pencegahan perdarahan pada saat persalinan akan mengurangi terjadinya komplikasi selama masa nifas dan akan mengurangi angka kematian ibu.

Perdarahan post partum meliputi 2 jenis yaitu: perdarahan post partum primer terjadi dalam 24 jam pertama penyebabnya diantaranya adalah atonia uteri, retensio plasenta, sisa plasenta, dan robekan jalan lahir. Perdarahan pospartum sekunder terjadi setelah 24 jam pertama penyebabnya diantaranya adalah robekan jalan lahir dan sisa plasenta atau membran.

Berdasarkan data survey awal yang dilakukan di RSI NASHRUL UMMAH Lamongan pada bulan Januari sampai 
Desember tahun 2014 terdapat 554 ibu nifas, dengan kasus perdarahan sebanyak 22 orang $(3.97 \%)$, antara lain : perdarahan yang disebabkan sisa plasenta sebanyak 10 orang $(1.8 \%)$, atonia uteri sebanyak 3 orang $(0,54 \%)$, retensio plasenta sebanyak 4 orang $(0,72 \%)$, dan robekan jalan lahir sebanyak 5 orang $(0,90 \%)$.

Upaya yang dapat dilakukan untuk mencegah terjadinya perdarahan post partum yaitu mencegah faktor resiko penyebab terjadinya post partum.

Tujuan penelitian ini adalah mendapat gambaran nyata tentang teori dan praktek lapangan untuk mengembangkan pola pikir dalam melaksanakan asuhan kebidanan dengan menggunakan manajemen kebidanan (SOAP) pada Asuhan Kebidanan Komprehensif Ny"C" P2002 dengan post HPP karena retensio plasenta di RSUD dr.Soegiri lamongan tahun 2015.

\section{PEMBAHASAN}

\section{Pengkajian Data Subyektif}

Pada studi kasus post partum dengan Haemoragic post partum (HPP) karena retensio plasenta didapatkan keluhan utama bahwa bayi sudah lahir ari- ari belum lahir mengeluarkan darah encer dari jalan lahir.

Pada tinjauan pustaka keluhan yang sering terjadi pada kasus haemoragic post partum antara lain perdarahan banyak dan bergumpal setelah melahirkan disebutkan bahwa perdarahan dikarenakan plasenta belum lahir.

Pada data subyektif terdapat kesenjangan antara tinjauan kasus dan tinjauan pustaka. Hal ini dikuatkan oleh teori Plasenta belum lahir setelah 30 menit ,perdarahan segera, kontraksi uterus baik. Gejala yang kadang timbul tali pusat terputus akibat traksi berlebihan .Tertinggalnya plasenta, gejala yang selalu ada plasenta tidak lengkap dan perdarahan segera (Ai Yeyeh Rukiyah, 2010).

\section{Pengkajian Data Obyektif}

Pada studi kasus Ny "C" post dengan Haemoragic post partum (HPP) karena retensio plasenta didapatkan hasil pemeriksaan pada tanda-tanda vital (TTV) : TD : 90/70 mmHg, RR : 24 x/menit, suhu : $36,5{ }^{\circ} \mathrm{C}$, nadi : $100 \mathrm{x} / \mathrm{menit}$. Penderita tampak anemis di tandai dengan konjungtiva pucat. Kontraksi uterus lembek, TFU 2 jari dibawah pusat, kandung kemih kosong, terdapat pengeluaran lochea rubra.

Pada tinjauan pustaka Haemoragic post partum (HPP) karena retensio plasenta adalah Adalah terlambatnya kelahiran plasenta selama setengah jam setelah kelahiran bayi dengan tanda gejala yaitu keadaan umum lemah, berkeringat dingin, pucat, TTV tensi turun $(<90$ $\mathrm{mmHg}$ ), nadi meningkat ( $>100 \mathrm{x} /$ menit). Pada palpasi TFU setinggi pusat, kontraksi uterus baik, kandung kemih Kosong.

Pada data obyektif terdapat kesejangan antar tinjauan kasus dan tinjauan pustaka. Hal ini di kuatkan oleh teori pada perdarahan melebihi $20 \%$ volume total, timbul gejala penurunan tekanan darah, nadi dan nafas cepat, pucat, ekstremitas dingin, sampai terjadi syok (Mansjoer, 2008).

\section{Analisa}

Pada studi kasus berdasarkan data pengkajian pada klien ditemukan diagnosa yaitu Ny. "C" $\mathrm{P}_{2002}$ post partum hari ke-1 dengan Haemoragic Post Partum (HPP) karena retensio plasenta. Masalah aktual yang terjadi adalah perdarahan karena retensio plasenta dan ditemukan masalah resiko tinggi terhadap infeksi, dan syok karena perdarahan (Syok Haemoragic).

Pada tinjauan pustaka Haemoragic post partum (HPP) karena retensio plasenta tidak semua kasus ini mengalami masalah potensial yang akan terjadi pada perdarahan karena retensio plasenta adalah infeksi dan syok karena kekurangan cairan, sedangkan pada tinjauan kasus tidak ditemukan tanda-tanda infeksi dan syok karena kekurangan cairan. 
Pada analisa terdapat persamaan antara tinjauan kasus dan tinjauan pustaka. Hal ini dikuatkan dengan teori yang menyebutkan bahwa Haemoragic post partum (HPP) karena retensio plasenta masalah potensialnya adalah infeksi dan perdarahan,syok, infeksi dan perforasi (Ai Yeyeh Rukiyah, 2010).

\section{Penatalaksanaan}

Pada penatalaksanaan studi kasus yang dilakukan pada pasien dengan perdarahan antara lain memberitahu pada ibu dan keluarga tentang keadaan ibu saat ini, memberi dukungan dan penjelasan singkat tentang perdarahan akibat tertinggalnya sisa placenta, melakukan informed consent sebagai persetujuan untuk melakukan tindakan, memperbaiki keadaan umum dengan rehidrasi agar keadaan klien membaik, memberitahu ibu dan keluarga tentang kemungkinan yang terjadi pada ibu karena perdarahan karena sisa placenta yaitu pasien dapat mengalami anemi, syock hemoragic, infeksi puerpuralis, melakukan kolaborasi dengan dokter Sp.OG untuk terapi dan tindakan, melakukan eksplorasi sisa plasenta, mengajarkan klien dan keluarga untuk massase fundus uteri, melakukan perbaikan keadaan umum dengan melakukan observasi TTV (tanda-tanda vital) tensi, suhu, nadi, dan respirasi tiap 8 jam/ hari, rehidrasi dan pemenuhan intake cairan per infus untuk mengetahui perkembangan keadaan umum ibu, melakukan pencatatan untuk pendokumentasi. lakukan penanganan pasca tinadakan, lakukan observasi (TTV, TFU, kontraksi uterus), lakukan perawatan luka.

Pada tinjauan teori penatalaksanaan yang dilakukan pada pasien dengan perdarahan karena retensio plasenta antara lain memberitahu pada ibu dan keluarga tentang keadaan ibu saat ini, memberi dukungan dan penjelasan singkat tentang perdarahan akibat tertinggalnya retensio placenta, melakukan informed consent sebagai persetujuan untuk melakukan tindakan, memperbaiki keadaan umum dengan rehidrasi agar keadaan klien membaik, memberitahu ibu dan keluarga tentang kemungkinan yang terjadi pada ibu karena perdarahan karena retensio placenta yaitu pasien dapat mengalami anemi, syock hemoragic, infeksi puerpuralis, melakukan kolaborasi dengan dokter Sp.OG untuk terapi dan tindakan, melakukan eksplorasi sisa plasenta, mengajarkan klien dan keluarga untuk massase fundus uteri, melakukan perbaikan keadaan umum dengan melakukan observasi tanda-tanda vital (TTV) tiap $8 \mathrm{jam} / \mathrm{hari}$, rehidrasi dan pemenuhan intake cairan per infus untuk mengetahui perkembangan keadaan umum ibu, melakukan pencatatan untuk pendokumentasi.

Pada penatalaksanaan terdapat persamaan antara tinjauan kasus dan tinjauan pustaka. Di kuatkan oleh teori bahwa kasus retensio plasenta dilakukan tindakan manual plasenta (Sarwono, 2008).

\section{KESIMPULAN \\ Simpulan}

Pada pengkajian subyektif tidak terdapat kesenjangan antara tinjauan pustaka dan tinjauan kasus pada keluhan utama. Pada pengkajian obyektif tidak terdapat kesenjangan antara tinjauan pustaka dan tinjauan kasus pada pemeriksaaan fisik. Pada Analisa terdapat kesenjangan antara tinjauan pustaka dengan tinjauan kasus pada masalah potensial. Pada penatalaksanaan tidak terdapat kesenjangan antara tinjauan pustaka dan tinjauan kasus pada penatalaksanaan.

Saran

Dapat dijadikan sebagai literatur untuk perkembangan dan penyempurnaan penelitian yang sudah ada khususnya kasus nifas dengan haemoragic post partum. Sebagai acuan untuk meningkatkan kualitas pelayanan sehingga tercapai asuhan kebidanan yang lebih komprehensif. 
Pemahaman tentang informasi yang berhubungan dengan haemoragic post partum akan membantu masyarakat dalam mendeteksi dini komplikasi dan tindakan yang harus dilakukan agar tidak terjadi hal yang tidak di inginkan.

\section{DAFTAR PUSTAKA}

Mansjoer, Arif, dkk. 2008: Kapita selekta kedokteran. Jakarta: Media Ausculapius. Fakultas Kedokteran Universitas Indonesia

Saifuddin, Abdul Bari. 2010 : Buku panduan praktis pelayanan kesehatan maternal dan neonatal. Jakarta : PT. Bina Pustaka Sarwono Prawirohardjo.

Rukiyah, Ai Yeyeh, dkk. 2010: Asuhan kebidanan patologi kebidanan. Jakarta Timur: CV. Trans Info Media 